\title{
Un programa de transferencias monetarias condicionadas contribuyó a disminuir la mortalidad infantil en Brasil
}

\author{
A conditional cash transfer program helped to reduce infant mortality in Brazil
}

Rasella D y col. Lancet 2013;382:57-64.

\section{Objetivos}

Evaluar el efecto del Programa Bolsa Familia (PBF) sobre la tasa de mortalidad en menores de cinco años en municipios seleccionados de Brasil haciendo foco en las causas de mortalidad asociadas con la pobreza (como la malnutrición, la diarrea y las infecciones respiratorias bajas) y en algunas actividades que tienden a disminuir la mortalidad infantil (como la vacunación, la atención prenatal y el acceso a hospitales).

\section{Diseño, lugar y periodo de estudio}

Estudio ecológico mixto, que utilizo al municipio como unidad de análisis. Se realizó sobre 2.853 de un total de 5.565 municipios existentes en Brasil entre 2004 a 2009.

\section{Fuente de datos}

Estadísticas gubernamentales de los Ministerios de Salud, Desarrollo Social y del Instituto de Geografía y Estadísticas.

\section{Intervención}

Los municipios seleccionados fueron clasificados, según el nivel de cobertura del PBF, en baja (de 0,0 a $17,1 \%$ de su población cubierta por el programa), intermedia (17,2 a 32,0\%), alta $(>32,0 \%)$ o consolidada $(>32,0 \%$ y al mismo tiempo con la cobertura del $100 \%$ de la población objetivo por lo menos durante los cuatro años previos). Se realizaron análisis de regresión multivariable con las estadísticas obtenidas ajustando por covariables sociales y económicas relevantes y por los efectos del Programa de Salud Familiar.

\section{Resultados principales}

La tasa de mortalidad en menores de cinco años así como las tasas específicas de mortalidad en menores de cinco años por causas asociadas a la pobreza disminuyeron al tiempo que se incrementó la cobertura del PBF. Así, la razón de tasas de mortalidad (RR) ajustadas para los efectos del PBF sobre la mortalidad global en menores de cinco años fueron de 0,94 (IC $95 \% 0,92$ a 0,96$)$ para los municipios de cobertura intermedia, $0,88(0,85$ a 0,95$)$ para los de alta cobertura, y $0,83(0,79$ a $0,88)$ para los de cobertura consolidada. El efecto del PBF en municipios con cobertura consolidada fue más alto para mortalidad en menores de cinco años por causa de malnutrición $(0,35 ; 0,24$ a 0,50$)$ y de diarrea $(0,47 ; 0,37$ a 0,61$)$.

El efecto del PBF fue mayor cuando, en municipios con alta cobertura, esta cobertura se mantuvo en forma total sobre la población objetivo de familias pobres por cuatro años o más. El PBF además redujo sustancialmente las tasas de ingresos hospitalarios en menores de cinco años, e incremento la cobertura de vacunación y controles prenatales.

\section{Conclusión de los autores}

Un programa de transferencias monetarias condicionadas puede contribuir de manera significativa a disminuir mortalidad infantil de manera global y en particular por muertes atribuibles a causas asociadas a la pobreza, como malnutrición y diarrea, en un país de ingresos medios como Brasil.

Fuente de financiamiento: Instituto Nacional de Ciencias y Tecnología, Ministerio de Ciencia y Tecnología y Agencia para el Desarrollo Científico y Tecnológico (CNPq), Brasil.

\section{Comentario}

Los programas de transferencias monetarias condicionadas (PTC) pueden mejorar la supervivencia en niños a través de diferentes mecanismos. El incremento de los ingresos monetarios puede mejorar el acceso a los alimentos y a otros bienes relacionados con la salud, y los condicionamientos exigidos pueden mejorar el acceso a los servicios de salud.

A finales de los 90 comenzaron a aplicarse en algunos países de América Latina programas sociales de transferencia de dinero desde el gobierno a las familias pobres a fin de mejorar sus ingresos. Estos programas establecen condiciones de salud y educación para la percepción de dichas transferencias. Estos PTC son programas complejos con múltiples actores involucrados de diferentes jurisdicciones y niveles de gobierno lo cual requiere de una gran coordinación de incentivos, tiempo y definición de roles ${ }^{1}$.

Los PTC requieren coordinación con las áreas de gobierno responsables de generar oferta de salud y educación las cuales no están bajo la directa responsabilidad de quien ejecuta el programa ${ }^{2}$.

Los PTC encarnan intervenciones de alto respaldo político y sólidos recursos presupuestarios, resultando fundamental lograr la coordinación entre quien provee la transferencia monetaria con los Ministerios de Educación y Salud, incluso en situaciones donde el manejo de ambos sectores depende de niveles subnacionales y/o locales ${ }^{3}$.

\section{Conclusiones del comentador}

El presente estudio apunta al diseño de las políticas públicas desde lo más alto del nivel gubernamental ya que aporta como novedad, no solo la efectividad de los PTC en disminuir la mortalidad en niños, sino además la importancia de implantar políticas públicas integrales que coordinen las diferentes áreas de gobierno.

Adolfo Sánchez de León [Jefe de Trabajos Prácticos de Salud Pública. Facultad de Medicina UNICEN. Olavarria. Argentina. adolfosanchezdeleon@yahoo.com.ar]

Sanchez de Leon Adolfo. Un programa de transferencias monetarias condicionadas contribuyó a disminuir la mortalidad infantil en Brasil. Evid Act Pract Ambul. $2015 ; 18$ (1) 7. Ene-Mar. Comentado de: Rasella D, et al. Effect of a conditional cash transfer programme on childhood mortality: a nationwide analysis of Brazilian municipalities. Lancet. 2013;382(9886):57-64. PMID: 23683599.

\section{Referencias}

1. Grosh Margaret. Conditional Cash Transfers (CCTs) around the world. Presentación realizada en el Instituto Interamericano para el Desarrollo Social, Banco Interamericano de Desarrollo, Washington DC, 2007.

2. Cohen Ernesto y Franco Rolando. Los programas de transferencias con corresponsabilidad en América Latina: similitudes y diferencias. En: Cohen Ernesto y Franco, Rolando (eds.). Transferencias con corresponsabilidad. Una mirada latinoamericana. FLACSO, México DF, 2006.

3. Repetto, Fabián. Coordinación de políticas sociales: abordaje conceptual y revisión de experiencias latinoamericanas. En: Jefatura de Gabinete de Ministros. Presidencia de la Nación, Los desafíos de la coordinación y la integralidad de las políticas y gestión pública en América Latina, Buenos Aires, 2010. 